\title{
Robotic bronchoscopy: is it classic?
}

\author{
Taichiro Goto $^{\wedge}$ \\ Lung Cancer and Respiratory Disease Center, Yamanashi Central Hospital, Yamanashi, Japan \\ Correspondence to: Taichiro Goto, MD. Lung Cancer and Respiratory Disease Center, Yamanashi Central Hospital, Yamanashi 400-8506, Japan. \\ Email: taichiro@1997.jukuin.keio.ac.jp. \\ Comment on: Agrawal A, Hogarth DK, Murgu S. Robotic bronchoscopy for pulmonary lesions: a review of existing technologies and clinical data. \\ J Thorac Dis 2020;12:3279-86
}

Submitted Oct 26, 2020. Accepted for publication Nov 26, 2020.

doi: $10.21037 /$ jtd-20-3088

View this article at: http://dx.doi.org/10.21037/jtd-20-3088

I read with interest the paper titled "Robotic bronchoscopy for pulmonary lesions: a review of existing technologies and clinical data" by Agrawal et al. (1). This article reviewed the existing robotic bronchoscopy technologies and summarized the available pre-clinical and clinical data supporting their use. Robotic bronchoscopy was reported to have achieved successful lesion localization in $96.2 \%$ of cases, with an adverse event rate comparable to those of conventional bronchoscopic procedures (2). However, its diagnostic yield in sampling peripheral lung lesions remains yet to be demonstrated.

I wish to discuss the implications of this review article and prospects for robotic bronchoscopy from the perspective of a thoracic surgeon. Robotic surgery has been widely adopted for mainly prostate surgery, and it can be safely said that nearly all cases of prostate surgery at present are robot-assisted (3). In robotic prostate surgery, dexterity and visualization are improved, while invasiveness is minimized; compared with open surgery, robotic surgery is safer and easier to perform (4). Because of these clear advantages, robotic prostate surgery is widely adopted. However, robotic cardiac surgery is not common in Japan even though it is covered by the National Health Insurance; the widespread adoption of robotic surgery might depend on whether the aforementioned advantages can be realized for cardiac surgery.

Then, what are the benefits of robotic bronchoscopy? In conventional bronchoscopy, surgeons are challenged by the narrow airways and complexities of the bronchial tree, which sometimes deter access to tumors (5). Although the procedural safety of robotic surgery has been ensured by compensating for the loss of tactile sense using a close, magnified view, is a similar strategy applicable to robotic bronchoscopy? Is the observable range (operable range) of robotic bronchoscopy more extensive in inherently narrow airways than that of conventional bronchoscopy? Should large-scale studies on robotic bronchoscopy, which entails no sensation of touching the airway epithelium, necessarily include some patients with airway trauma? In fact, a study involving 165 patients reported that airway bleeding occurred in $2.4 \%$ of the patients (6). With regard to the emergency treatment of biopsy-related bleeding, can the bronchoscope be safely wedged into the segmental bronchus responsible for the hemorrhagic focus without tactile sensation at the bronchoscope tip? I hope that in the future, the safety of robotic bronchoscopy will be verified in a broader scope, such as by considering emergency responses. Furthermore, in the future, prospective comparative studies should be conducted with diagnostic yield as the primary endpoint, with complications, procedural time, patient stress evaluations, and radiation exposure doses as the secondary endpoints.

Robotic bronchoscopy has wide applicability; further reduction of the scope diameter and more flexible maneuverability of the scope head may enable operations even in the branching patterns, which are difficult

$\wedge$ ORCID: 0000-0002-2560-3639. 
to navigate manually. In addition, I am personally hopeful that robotic surgical systems will acquire higher multifunctionality; the availability of functions such as a wiper system for cleaning the scope lens, visualization and recording systems for the surrounding and posterior views, a self-driving system that autonomously operates the fiberscope with guidance from a navigation system, a collision-avoidance system that always maintains the fiberscope at the center of the airway, and an emergency aid system that inflates an airway balloon in the event of bleeding can help increase the popularity of robotassisted bronchoscopy. In addition, if total automation and remote control are available, then aerosol avoidance during bronchoscopy may contribute toward effective prevention of nosocomial infection by pathogens such as the recent coronavirus (COVID-19) (7).

Further, what do bronchoscopists expect from further improvements to robotic bronchoscopy? Although the benefits of robotic bronchoscopy may be limited in the current scenario, this review article has suggested its safety and clinical applicability as an important first step toward future development. I expect that, along with the parallel development and promotion of new technologies and their validation through clinical trials, robotic bronchoscopy could be established as a new clinical standard within the next 10 years, similar to the da Vinci robotic prostate surgery.

\section{Acknowledgments}

Funding: None.

\section{Footnote}

Provenance and Peer Review: This article was a free submission to the journal. The article did not undergo external peer review.

Conflicts of Interest: The author has completed the ICMJE uniform disclosure form (available at http://dx.doi. org/10.21037/jtd-20-3088). The author has no conflicts of interest to declare.

Cite this article as: Goto T. Robotic bronchoscopy: is it classic? J Thorac Dis 2021;13(1):409-410. doi: 10.21037/jtd-203088
Ethical Statement: The author is accountable for all aspects of the work and is ensuring that questions related to the accuracy or integrity of any part of the work are appropriately investigated and resolved.

Open Access Statement: This is an Open Access article distributed in accordance with the Creative Commons Attribution-NonCommercial-NoDerivs 4.0 International License (CC BY-NC-ND 4.0), which permits the noncommercial replication and distribution of the article with the strict proviso that no changes or edits are made and the original work is properly cited (including links to both the formal publication through the relevant DOI and the license). See: https://creativecommons.org/licenses/by-nc-nd/4.0/.

\section{References}

1. Agrawal A, Hogarth DK, Murgu S. Robotic bronchoscopy for pulmonary lesions: a review of existing technologies and clinical data. J Thorac Dis 2020;12:3279-86.

2. Chen AC, Pastis NJ Jr, Mahajan AK, et al. Robotic Bronchoscopy for Peripheral Pulmonary Lesions: A Multicenter Pilot and Feasibility Study (BENEFIT). Chest 2020. [Epub ahead of print]. doi: 10.1016/ j.chest.2020.08.2047.

3. Liu S, Hemal A. Techniques of robotic radical prostatectomy for the management of prostate cancer: which one, when and why. Transl Androl Urol 2020;9:906-18.

4. Falagario U, Veccia A, Weprin S, et al. Robotic-assisted surgery for the treatment of urologic cancers: recent advances. Expert Rev Med Devices 2020;17:579-90.

5. Fielding $\mathrm{D}$, Oki $\mathrm{M}$. Technologies for targeting the peripheral pulmonary nodule including robotics. Respirology 2020;25:914-23.

6. Chaddha U, Kovacs SP, Manley C, et al. Robot-assisted bronchoscopy for pulmonary lesion diagnosis: results from the initial multicenter experience. BMC Pulm Med 2019;19:243.

7. Pritchett MA, Oberg CL, Belanger A, et al. Society for Advanced Bronchoscopy Consensus Statement and Guidelines for bronchoscopy and airway management amid the COVID-19 pandemic. J Thorac Dis 2020;12:1781-98. 